19 Revue d'histoire du XIXe siècle

Société d'histoire de la révolution de 1848 et des

révolutions du XIXe siècle

$19 \mid 1999$

Aspects de la production culturelle au XIXe siècle

\title{
Revue d'histoire des sciences humaines
}

\section{Pierre Lenoël}

URL : http://journals.openedition.org/rh19/175

DOI : $10.4000 /$ rh 19.175

ISSN : $1777-5329$

\section{Éditeur}

La Société de 1848

\section{Édition imprimée}

Date de publication : 1 décembre 1999

Pagination : 160

ISSN : 1265-1354

Référence électronique

Pierre Lenoël, «Revue d'histoire des sciences humaines », Revue d'histoire du XIXe siècle [En ligne], 19

1999, mis en ligne le 26 août 2008, consulté le 22 septembre 2020. URL : http://

journals.openedition.org/rh19/175; DOI : https://doi.org/10.4000/rh19.175

Ce document a été généré automatiquement le 22 septembre 2020.

Tous droits réservés 


\title{
Revue d'histoire des sciences humaines
}

\author{
Pierre Lenoël
}

1 Cette nouvelle revue bi-annuelle dont le premier numéro est paru en octobre 1999 est éditée par les Presses universitaires du Septentrion. Partant du fait que l'histoire des sciences humaines n'est pas seulement une écriture commémorative, l'ambition des animateurs de la revue est " de se tourner vers l'histoire non pour en reconstruire le sens à travers le filtre des interrogations, débats et combats d'aujourd'hui, mais pour tenter d'en comprendre le déroulement et l'évolution tels qu'ils se sont produits ". La revue se veut un lieu de rencontres et de débats, elle publie en français et en anglais. Au sommaire du premier numéro un important dossier sur "Maurice Halbwachs et les sciences humaines de son temps " et des critiques de livres sur l'histoire de la psychopathologie, l'histoire de l'ethnologie et l'histoire de l'économie politique.

Le prochain numéro annoncé pour avril 2000 aura pour thème : les correspondances; qu'est ce que la psychologie?

Renseignements: Isabelle Passégué (Secrétariat de rédaction), CESDIP, 43 boulevard Vauban, 78280 Guyancourt, Tél. : 0134521701 ; Fax. : 0134521717.

Abonnements: Presses universitaires du Septentrion, rue du barreau, BP 199, 59654 Villeneuve-d'Ascq cedex, Tél. : 0320416680 ; Fax. : 0320416690. 